\title{
Reduced Hippocampal Neurogenesis in Adult Transgenic Mice with Chronic Astrocytic Production of Interleukin-6
}

\author{
Luc Vallières, ${ }^{1}$ lain L. Campbell,, ${ }^{3}$ Fred H. Gage, ${ }^{2}$ and Paul E. Sawchenko ${ }^{1}$ \\ Laboratories of ${ }^{1}$ Neuronal Structure and Function and ${ }^{2}$ Genetics, The Salk Institute for Biological Studies, La Jolla, \\ California 92037, and '3epartment of Neuropharmacology, The Scripps Research Institute, La Jolla, California 92037
}

\begin{abstract}
Postnatal neurogenesis can be modulated after brain injury, but the role of the attendant expression of inflammatory mediators in such responses remains to be determined. Here we report that transgenically directed production of interleukin-6 (IL-6) by astroglia decreased overall neurogenesis by $63 \%$ in the hippocampal dentate gyrus of young adult transgenic mice. The proliferation, survival, and differentiation of neural progenitor cells labeled with the thymidine analog bromodeoxyuridine were all reduced in the granule cell layer of these mice, whereas their distribution and gliogenesis appeared normal. These ef-
\end{abstract}

fects were not a consequence of general toxicity of the IL-6 transgene, because they were manifested in the absence of neuronal death and of major changes in glial cell number and morphology. These findings suggest that long-term exposure of the brain to proinflammatory mediators such as IL-6, as is seen in certain degenerative disorders and infections, can interfere with adult neurogenesis.

Key words: postnatal neurogenesis; neural progenitor cells; interleukin-6; proinflammatory cytokine; chronic inflammation; hippocampus; transgenic mice; Fluoro-jade
The hippocampal dentate gyrus of adult mammals produces new neurons daily throughout life (Gross, 2000). The events that underlie this manifestation of postnatal neurogenesis begin with the proliferation of multipotent progenitor cells in a discrete area called the subgranular zone. Under the influence of site-specific molecular cues, a subpopulation of newly born cells migrates into the adjacent granule cell layer and differentiates into neurons. Such precursors are recruited in variable numbers, ostensibly as a function of physiological need, and become indistinguishable from other granule neurons because they express markers (Cameron et al., 1993; Okano et al., 1993; Kuhn et al., 1996), issue axonal projections (Stanfield and Trice, 1988; Markakis and Gage, 1999), and receive synaptic connections (Kaplan and Hinds, 1977; Kaplan and Bell, 1984), all in a manner characteristic of this population. Although the role of adult neurogenesis remains to be fully elucidated, recent findings suggest an important role in cognitive function (Kempermann et al., 1997; Gould et al., 1999; Shors et al., 2001).

The rate of progenitor proliferation in the dentate gyrus can be profoundly accelerated by insults such as cerebral ischemia (Liu et al., 1998), seizure (Bengzon et al., 1997; Parent et al., 1997) and neurotoxic lesions (Gould and Tanapat, 1997). A common sequela of brain injury that might contribute to such a response is the appearance of inflammatory mediators in the afflicted areas. The possibility that inflammation may influence neurogenesis has never been examined, but is consistent with the view that similar

Received Aug. 29, 2001; revised Oct. 26, 2001; accepted Oct 29, 2001.

This work was supported by National Institutes of Health Grants NS21182, MH50426, AGO6088, and AGO5131, by the Christopher Reeve Paralysis Foundation, and by the Lookout Fund. P.E.S. is an Investigator of the Foundation for Medical Research. L.V. was supported by postdoctoral fellowships from the Canadian Institutes of Health Research, the Canadian Neurotrauma Research Program, and Novartis. We thank Carrie Kincaid for assistance with the breeding and screening of mice used in this study.

Correspondence should be addressed to Paul E. Sawchenko, Laboratory of Neuronal Structure and Function, The Salk Institute for Biological Studies, 10010 North Torrey Pines Road, La Jolla, CA 92037. E-mail: sawchenko@salk.edu. Copyright (C) 2002 Society for Neuroscience $0270-6474 / 02 / 220486-07 \$ 15.00 / 0$ signaling pathways can regulate neural and hematopoietic progenitor cells (Scheffler et al., 1999). This raises questions about the consequences of long-term CNS inflammation (as occurs in degenerative and infectious diseases) on the survival and differentiation of neuronal precursors. Inflammatory mediators are pleiotropic and therefore might affect neurogenesis in multiple and unexpected ways.

Of particular interest in this regard is interleukin-6 (IL-6), a proinflammatory cytokine secreted primarily, and perhaps exclusively, in the brain under pathological circumstances (MunozFernandez and Fresno, 1998). Best known as a regulator of hematopoiesis, IL-6 is used to maintain the proliferation and survival of bone marrow progenitors in culture (Eglitis and Mezey, 1997; Peters et al., 1998). It is not known whether IL-6 might similarly affect neural progenitors, but this might be expected based on the presence of its receptor subunits in the dentate gyrus (Vallières and Rivest, 1997) and its capacity to promote the survival, differentiation, and growth of neurons (Munoz-Fernandez and Fresno, 1998). However, other evidence suggests that IL-6 might instead restrain neurogenesis by directing progenitor cells toward a glial lineage, because embryonic cerebral precursors differentiate into astrocytes when cultured in the presence of IL-6 (Bonni et al., 1997).

To test the hypothesis that IL- 6 can influence adult neurogenesis, we examined the proliferation, survival, and differentiation of neural progenitors in the dentate gyrus of transgenic mice that chronically express IL-6 in astroglia. Hemizygotes, which express the transgene at relatively low levels, were analyzed at an age at which only minor histopathological changes and no learning deficits have been observed (Campbell et al., 1993; Heyser et al., 1997).

\section{MATERIALS AND METHODS}

Animals. Transgenic mice expressing IL-6 under control of the glial fibrillary acidic protein (GFAP) promoter were generated as described previously (Campbell et al., 1993). The present study used hemizygous offspring of the G167 line at 3-4 months of age. These mice carried four 
copies of the IL-6 transgene and coexpressed the lac $Z$ reporter gene. Age- and sex-matched nontransgenic littermates were used as controls. The animals were housed four or five per cage and adapted to standard laboratory conditions for a week before any manipulation.

Bromodeoxyuridine injection. Bromodeoxyuridine (BrdU; Sigma, St. Louis, MO) was dissolved in nonpyrogenic $0.9 \% \mathrm{NaCl}$ at a concentration of $10 \mu \mathrm{g} / \mu \mathrm{l}$ and filtered at $0.2 \mu \mathrm{m}$. To label dividing cells, the mice received one daily injection of $\operatorname{BrdU}(50 \mu \mathrm{g} / \mathrm{gm}$ of body weight, i.p.) for 5 consecutive days. Mice were killed $1 \mathrm{~d}$ ( 8 transgenics, 9 controls) or $31 \mathrm{~d}$ ( 9 transgenics, 9 controls) after the final injection.

Seizure induction. A short-term seizure model was used to provide comparisons for any neuropathology observed as a consequence of IL-6 transgene expression. As described previously (Turski et al., 1984), mice were pretreated with scopolamine methyl nitrate $(1 \mathrm{mg} / \mathrm{kg}$ in saline, s.c.; Sigma) and treated $30 \mathrm{~min}$ later with the muscarinic agonist pilocarpine hydrochloride (340 mg/kg in saline, i.p.; Sigma). Seizures were terminated after $3 \mathrm{hr}$ with diazepam $(10 \mathrm{mg} / \mathrm{kg}$, i.p.; Elkins-Sinn, Cherry Hill, $\mathrm{NJ})$. The animals were then hydrated with $0.5 \mathrm{ml}$ of lactated Ringer's solution. Control animals were treated identically, except that pilocarpine was replaced by saline.

Tissue processing. The animals were anesthetized and perfused transcardially with $7 \mathrm{ml}$ of saline followed by ice-cold $4 \%$ paraformaldehyde in phosphate buffer, $\mathrm{pH} \mathrm{7.4,} \mathrm{for} 10 \mathrm{~min}$. Their brains were removed, post-fixed for $1 \mathrm{~d}$ at $10^{\circ} \mathrm{C}$, and then cryoprotected overnight in the same fixative supplemented with $20 \%$ sucrose. Sections were cut with a freezing microtome through the hippocampus at $30 \mu \mathrm{m}$. Four 1-in-5 series were collected in cryoprotectant (30\% ethylene glycol, $20 \%$ glycerol, 50 $\mathrm{mm}$ sodium phosphate buffer, $\mathrm{pH} 7.4$ ) and stored at $-20^{\circ} \mathrm{C}$ until histochemical analysis.

$B r d U$ detection. To allow for the detection of BrdU-labeled cells (see below), sections were pretreated for $30 \mathrm{~min}$ in $2 \mathrm{~N} \mathrm{HCl}$ at $37^{\circ} \mathrm{C}$ to denature DNA. The sections were then incubated for $10 \mathrm{~min}$ in $100 \mathrm{~mm}$ sodium borate, $\mathrm{pH} 8.5$, to neutralize residual acid. For multiple immunofluorescence labeling, BrdU pretreatment and immunolabeling were performed after staining for glial and neuronal markers.

Immunoperoxidase. Free-floating sections were treated with $0.3 \%$ $\mathrm{H}_{2} \mathrm{O}_{2}$ for $30 \mathrm{~min}$ to inhibit endogenous peroxidase activity. Background staining was blocked by incubating the sections for $30 \mathrm{~min}$ in $50 \mathrm{~mm}$ potassium PBS (KPBS) containing 5\% goat serum and $0.4 \%$ Triton $\mathrm{X}-100$. Using the same buffer solution, the sections were incubated overnight at $10^{\circ} \mathrm{C}$ in primary antibody [monoclonal rat anti-BrdU (Harlan Sera-Lab, Loughborough, UK); polyclonal rabbit anti- $\beta$ galactosidase (anti- $\beta$-gal; ICN Biochemicals, Costa Mesa, CA)] followed by incubation for $2 \mathrm{hr}$ at room temperature in corresponding peroxidaseconjugated goat secondary antibody (Jackson ImmunoResearch, West Grove, PA). Staining was developed for 5-7 min in nickel-DAB solution $(2.5 \%$ nickel ammonium sulfate, $100 \mathrm{~mm}$ sodium acetate, $0.5 \mathrm{mg} / \mathrm{ml}$ $\mathrm{DAB}, 2 \mathrm{mg} / \mathrm{ml} \beta$-D(+)-glucose, $0.4 \mathrm{mg} / \mathrm{ml}$ ammonium chloride, and 1 $\mu \mathrm{l} / \mathrm{ml}$ glucose oxidase). Each of the above steps was followed by four 5 min rinses in KPBS. The sections were mounted onto gelatin-coated slides, and some were counterstained with $1 \%$ neutral red in $4 \mathrm{~mm}$ sodium acetate, $\mathrm{pH} 2.8$, dehydrated, and coverslipped with DPX (BDH Chemicals, Poole, UK).

Immunofluorescence. Free-floating sections were incubated for $30 \mathrm{~min}$ in KPBS containing $5 \%$ goat serum and $0.4 \%$ Triton $\mathrm{X}-100$. Using the same buffer solution, the sections were incubated overnight at $10^{\circ} \mathrm{C}$ in primary antibody [monoclonal rat anti-BrdU (Harlan Sera-Lab); polyclonal rabbit anti-GFAP (Chemicon, Temecula, CA); polyclonal guinea pig anti-GFAP (Advanced ImmunoChemical, Long Beach, CA); monoclonal mouse anti-neuron-specific nuclear protein (NeuN; Chemicon); polyclonal rabbit anti-S100 $\beta$ (Swant, Bellizona, Switzerland); polyclonal rabbit anti-ionized calcium-binding adapter molecule 1 (Iba-1; Ito et al., 1998; provided by Dr. Y. Imai, National Institute of Neuroscience, Tokyo, Japan)], followed by $2 \mathrm{hr}$ at room temperature in corresponding fluorochrome-conjugated goat secondary antibody (anti-guinea pig FITC, anti-mouse FITC, anti-rabbit Cy5, anti-rabbit FITC, anti-rabbit rhodamine Red-X (RRX), and anti-rat RRX; all from Jackson ImmunoResearch). Each of the above steps was followed by four 5 min rinses in KPBS. The sections were mounted onto gelatin-coated slides, dried, and coverslipped with ProLong antifade medium (Molecular Probes, Eugene, OR).

Fluoro-jade staining. Fluoro-jade is an anionic fluorescein derivative that is used to stain degenerating neurons selectively (Schmued et al., 1997). After pilocarpine-induced seizures, neurons labeled positively for this marker consistently lack diamidinophenylindole dihydrochloride
(DAPI)-stainable nuclei, suggesting that Fluoro-jade labels neurons that are undergoing irreversible degeneration (our unpublished observations). Brain sections were mounted onto gelatin-coated slides. When fully dried, the slides were immersed in $100 \%$ ethanol for $3 \mathrm{~min}$, followed by immersion for $1 \mathrm{~min}$ each in $70 \%$ ethanol, $50 \%$ ethanol, and distilled water. The slides were then transferred to a solution of $0.06 \%$ potassium permanganate for $10 \mathrm{~min}$ to block background staining. After an additional rinse in water, the sections were stained for $20 \mathrm{~min}$ in $0.004 \%$ Fluoro-jade B (Histochem, Jefferson, AK), 0.0002\% DAPI (Molecular Probes), and $0.1 \%$ acetic acid. The slides were then rinsed in water three times for $1 \mathrm{~min}$, dried, soaked in xylene, and coverslipped with DPX.

Cell counting and volumetric analysis. Cell counts were performed by an observer who was unaware of the treatment status of the animals. For each animal, a complete series of 1-in-5 sections through the dorsal dentate gyrus was analyzed with a light microscope at $600 \times$ magnification. The number of BrdU-labeled profiles was counted in the granule cell layer and the hilar region. We defined the granule cell layer as including the areas $10 \mu \mathrm{m}$ deep in the subgranular zone and $5 \mu \mathrm{m}$ deep in the molecular layer. The hilus was defined as the area enclosed by the granule cell layer and a virtual straight line that joined the tips of its two blades. The total number of BrdU-positive cells was estimated by multiplying the number of profiles by 5 and applying Abercrombie's correction (Abercrombie, 1946). Although not an accurate estimate of the absolute cell number, this method permits a meaningful comparison of differences between groups. For cell phenotyping, 40 BrdU-positive cells per animal were analyzed for colocalization with NeuN or S100 $\beta$ by confocal laser microscopy with a $63^{\prime}$ objective. To estimate the volume of the granule cell layer, sections were stained with DAPI and analyzed using a $10^{\prime}$ objective and a semiautomatic stereology system (StereoInvestigator; MicroBrightField, Colchester, VT). The total volume was calculated by summing the traced granule cell areas for each section and multiplying by the section thickness and the sampling interval. The granule cell diameter was measured on Nissl-stained sections using a $40 \times$ objective and the stereology system. Data were analyzed by ANOVA followed by Scheffé's test for post hoc multiple comparisons.

\section{RESULTS}

\section{IL-6 transgene expression}

As reported previously (Campbell et al., 1993; Brochu et al., 1999), IL-6 mRNA was not detectable by in situ hybridization in the brains of wild-type mice under basal conditions (data not shown). To examine the distribution of IL-6 transgene expression in hemizygous transgenic mice at 4-5 months of age, expression of the lac $Z$ reporter gene was assessed by immunohistochemical detection of $\beta$-gal. The distribution of this marker has been found to overlap with that of the mRNA encoding the IL- 6 transgene (Campbell et al., 1993), and provides better morphologic definition of cells expressing the transgene. Cells positive for $\beta$-gal were detected throughout all hippocampal subfields (Fig. 1B), including the dentate gyrus (Fig. $1 C$ ), in which many labeled cells were located at the interface between the granule cell layer and the hilar region. IL-6 transgene expression was evident in a number of different types of astrocytes, including radial-like astrocytes within the granule cell layer (Fig. 1D), protoplasmic astrocytes of the gray matter (Fig. 1E), and blood vesselassociated astrocytes (Fig. $1 F$ ). In forebrain sections spanning the rostrocaudal extent of the hippocampal formation, the majority of $\beta$-gal-positive cells were found in the hippocampus, with only scattered immunopositive cells observed in the hypothalamus (arcuate nucleus, median eminence) and meninges (data not shown). $\beta$-gal-immunoreactive cells were detected in the cerebral cortex and thalamus in only four of nine transgenic animals, manifested principally as a small number of positive cells localized primarily to the retrosplenial cortex and the lateral dorsal nucleus of the thalamus (Fig. $1 B$ ). This heterogeneity of transgene expression is unexplained, but it seems to correlate with regions of the normal brain that show the highest levels of GFAP expression (Kalman and Hajos, 1989). 


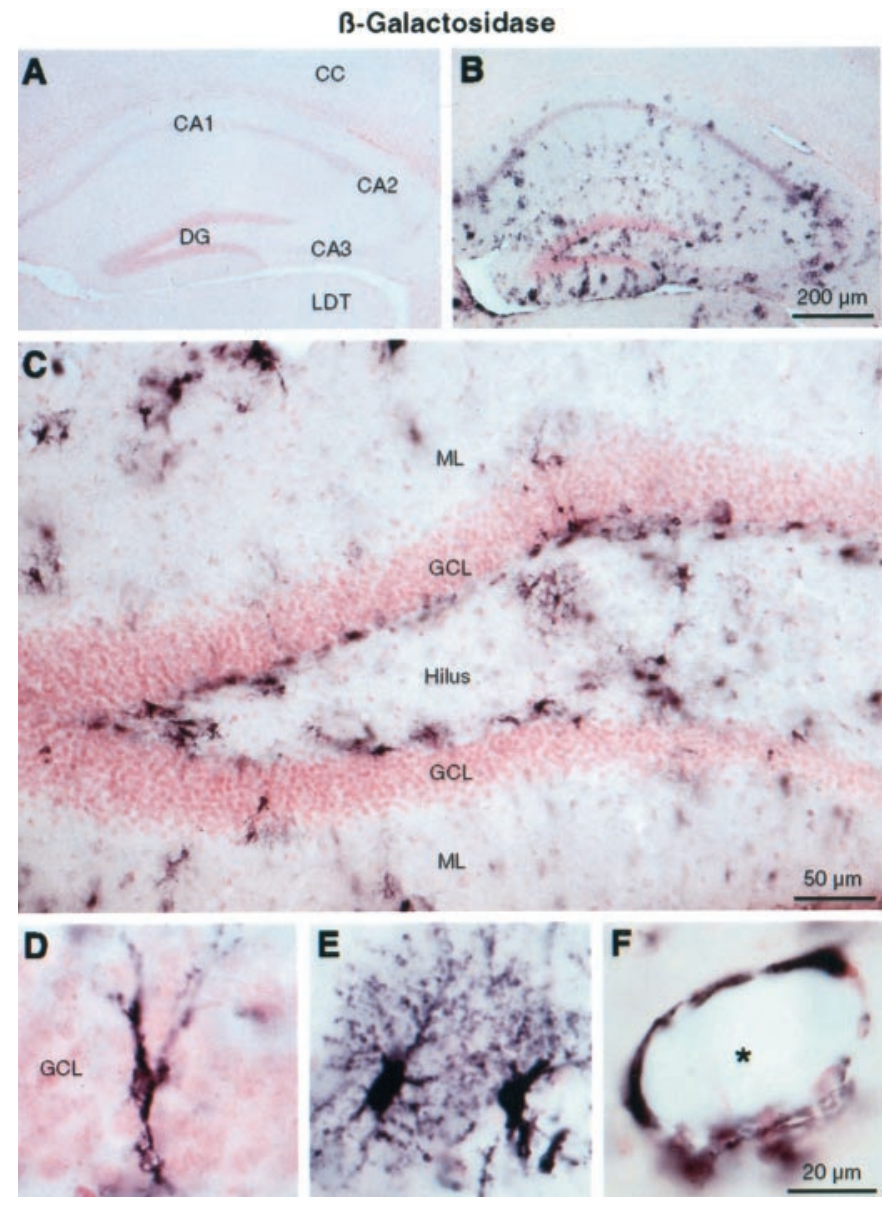

Figure 1. IL-6 transgene expression in the hippocampus revealed by $\beta$-gal immunohistochemistry. Brightfield photomicrographs of neutral red counterstained material show a lack of $\beta$-gal staining in the hippocampus of a wild-type mouse $(A) ; \beta$-gal staining in the hippocampus of an IL-6 transgenic mouse $(B)$; higher magnification of $\beta$-gal staining in the dentate gyrus, showing many positive cells at the border between the granule cell layer and the hilus $(C)$; a radial-like astrocyte within the granule cell layer expressing the IL-6 transgene $(D)$; protoplasmic astrocytes of the gray matter $(E)$; and blood vessel-associated astrocytes $(F)$. CA1-CA3, Fields CA1-CA3 of Ammon's horn; $C C$, cerebral cortex; $D G$, dentate gyrus; $G C L$, granule cell layer; $L D T$, lateral dorsal thalamic nucleus; $M L$, molecular layer. The asterisk indicates lumen of blood vessel.

\section{Neuronal integrity and gliosis}

Because the extent of neuropathological changes in mice that chronically express IL-6 in the CNS varies as a function of strain and age (Campbell et al., 1993; Chiang et al., 1994), neuronal integrity and gliosis were analyzed in the young adult transgenic mice tested in the present study. Staining with Fluoro-jade, a marker for degenerating neurons (Schmued et al., 1997), revealed a complete absence of labeled cells in the brains of both IL-6 transgenic and wild-type mice (Fig. $2 A, B$ ). In contrast, many Fluoro-jade-positive cells were found in the dentate gyrus of control animals subjected to pilocarpine-induced seizures (Fig. $2 C$ ) or adrenalectomy (data not shown). On the other hand, the astrocyte marker GFAP revealed a relatively mild astrogliosis in $\sim 40 \%$ of transgenic mice compared with their littermate controls (Fig. 2D,E). However, astrocytic morphology was similar between the transgenic and wild-type mice and differed substantially from that of the reactive astrocytes seen in mice subjected to seizures (Fig. $2 F$ ). Finally, the microglial marker Iba-1 (Ito et al., 1998) revealed a clear microgliosis in transgenic mice (Fig. $2 G, H)$. However, the appearance of the microglial cells in the transgenic mice was normal and quite distinct from the hypertrophied microglia seen reliably after seizures (Fig. 2I).

\section{Progenitor proliferation}

To evaluate progenitor cell proliferation in the dentate gyrus, BrdU-labeled cells were counted in mice killed $1 \mathrm{~d}$ after the last of five daily BrdU injections (Fig. $3 A, B$ ). Within the area encompassing the granule cell layer and subgranular zone, the mean $( \pm$ SEM) number of BrdU-positive cells estimated in the dorsal hippocampus was $1062 \pm 150$ in transgenic mice versus $1449 \pm$ 126 in wild-type mice, corresponding to a $27 \%$ reduction $(p=$ 0.05 ) (Fig. $3 A$ ). In the hilar region, no significant between-group differences were observed in the number of BrdU-labeled cells (wild-type, $276 \pm 31$; transgenic, $323 \pm 37 ; p>0.05$ ) (Fig. 3B), suggesting that BrdU bioavailability within the hippocampus was similar between the groups. The distribution of the dividing cells in the transgenic mice was not obviously different from the distribution seen in controls, with these cells being found most commonly in clusters at the border between the granule cell layer and the hilus (Fig. 4A,B).

\section{Progenitor survival}

The survival of progenitor cells was examined in the dentate gyrus $31 \mathrm{~d}$ after the last BrdU injection (Fig. $3 A, B$ ). In the granule cell layer and subgranular zone, estimates of the total dorsal hippocampal BrdU-positive population were $500 \pm 66$ in transgenic mice and $1074 \pm 104$ in wild-type mice, amounting to a 53\% reduction $(p<0.01$; Fig. $3 A$ ). When compared with the values obtained for the corresponding groups killed $1 \mathrm{~d}$ after the final injection, the number of surviving BrdU-labeled cells declined to a greater degree in the transgenic mice $(53 \% ; p<0.01)$ than in the wild-type mice $(26 \% ; p>0.05)$. This reduction was not attributable to changes in the volume or cell density of the granule cell layer as a consequence of transgene expression, because neither volumetric measures (wild-type, $0.410 \pm 0.009$ $\mathrm{mm}^{3}$; transgenic, $\left.0.404 \pm 0.010 \mathrm{~mm}^{3} ; p=0.66\right)$ nor cell diameter measures (wild-type, $10.07 \pm 0.18 \mu \mathrm{m}$; transgenic, $10.15 \pm 0.16$ $\mu \mathrm{m} ; p=0.72$ ) differed significantly between the groups. In the hilus, no significant difference was observed in the number of BrdU-positive cells between the groups that survived $31 \mathrm{~d}$ (transgenic, $134 \pm 18$; wild-type, $217 \pm 55 ; p>0.05)($ Fig. $3 B)$. The distribution of the surviving cells in the transgenic mice was apparently normal (Fig. 4C,E), with labeled cells found most commonly at the border between the granule cell layer and the hilus or within the granule cell layer.

\section{Progenitor differentiation}

Progenitor cell differentiation was examined at $31 \mathrm{~d}$ after BrdU injection by concurrent immunolabeling for BrdU with neuronal $(\mathrm{NeuN})$ and glial (S100 $\beta$ ) markers (Fig. 5). S100 $\beta$ was preferred over GFAP because it serves as a marker for both types of macroglia and labels cell bodies with better definition and with comparable intensities in both groups. The percentage of BrdUpositive cells that colabeled for NeuN was $18 \%$ less in transgenic mice $(44 \pm 5 \%)$ than in wild-type mice $(62 \pm 5 \% ; p<0.01)$, whereas the percentage of BrdU-positive cells that also expressed $\mathrm{S} 100 \beta$ did not differ reliably between the groups (transgenic, $10 \pm$ $2 \%$; wild-type, $8 \pm 1 \%$; $p>0.05$ ). Consequently, a somewhat higher percentage of BrdU-positive cells in transgenic mice labeled for neither NeuN nor S100 $\beta(46 \pm 6 \%$ vs $30 \pm 5 \%$ cells in wild-type mice; $p<0.01)$. By multiplying the number of BrdU- 

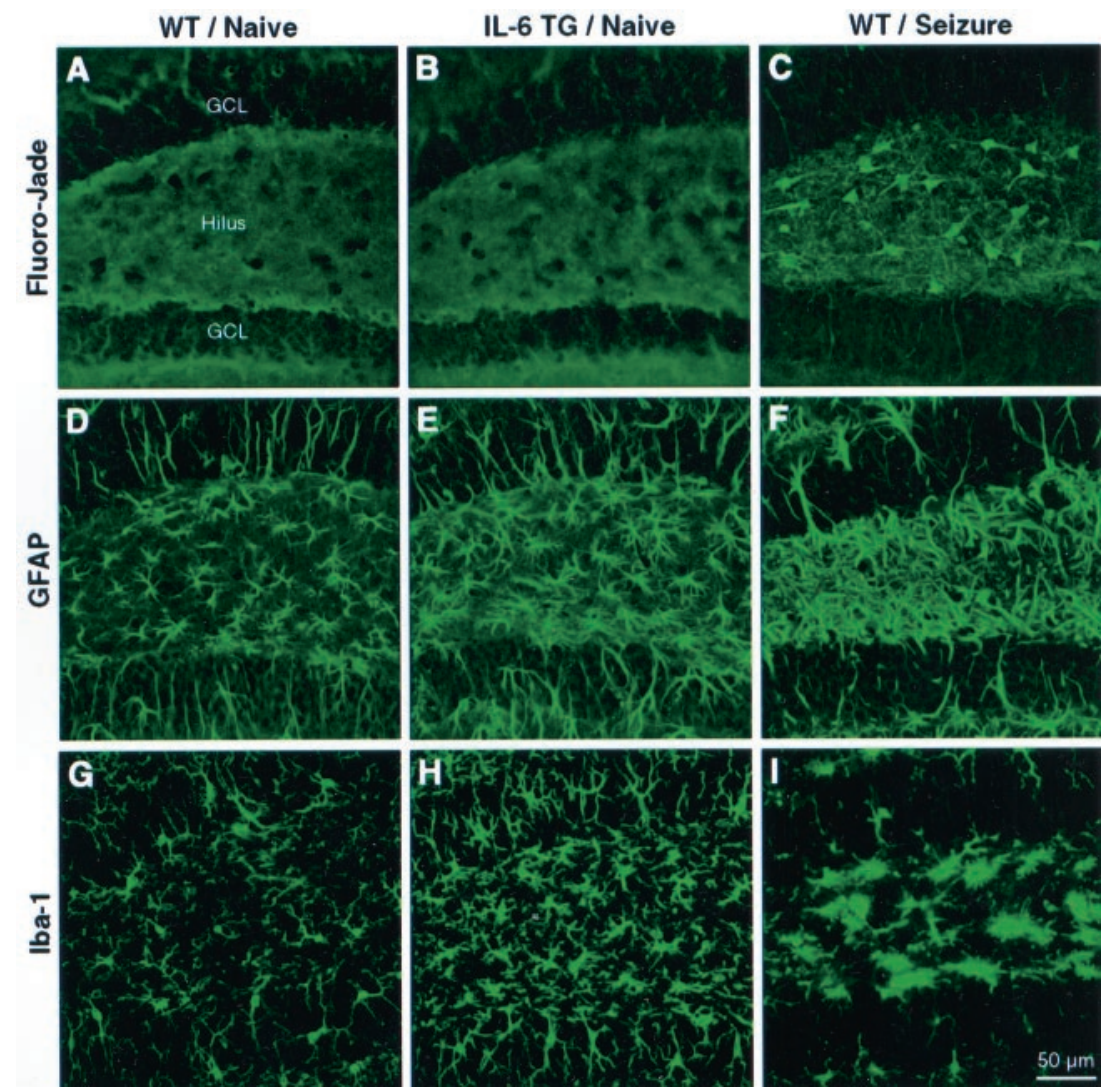

Figure 2. Neuronal integrity and gliosis in the dentate gyrus revealed by Fluoro-jade, GFAP, and Iba- 1 histochemistry. Confocal laser scanning microscopic images of sections through the dentate gyrus show absence of Fluoro-jade staining in a wild-type $(W T)$ mouse $(A)$, absence of Fluoro-jade staining in an IL-6 transgenic $(T G)$ mouse $(B)$, Fluoro-jade-positive cells in the hilar region of a control mouse subjected to seizures $(C)$, GFAP immunoreactivity in a WT mouse $(D)$, GFAP immunostaining indicative of a mild astrogliosis in a TG mouse $(E)$, hypertrophic reactive astrocytes in the hilus of a control mouse after seizures $(F)$, Iba-1 immunoreactivity in a WT mouse $(G)$, Iba-1 immunostaining indicating a moderate microgliosis in a TG mouse $(H)$, and rounded, hypertrophied microglia in the hilus of a control mouse after seizures $(I)$. GCL, Granule cell layer. labeled cells in subjects from the $31 \mathrm{~d}$ groups by the percentage of these cells that coexpressed NeuN, we estimate that the number of neurons produced in 1 month was $\sim 63 \%$ less in the transgenic mice $(254 \pm 68)$ than in the wild-type mice $(691 \pm 109)$.

\section{DISCUSSION}

Based on evidence that brain injury can enhance postnatal neurogenesis, the present study was undertaken to examine whether

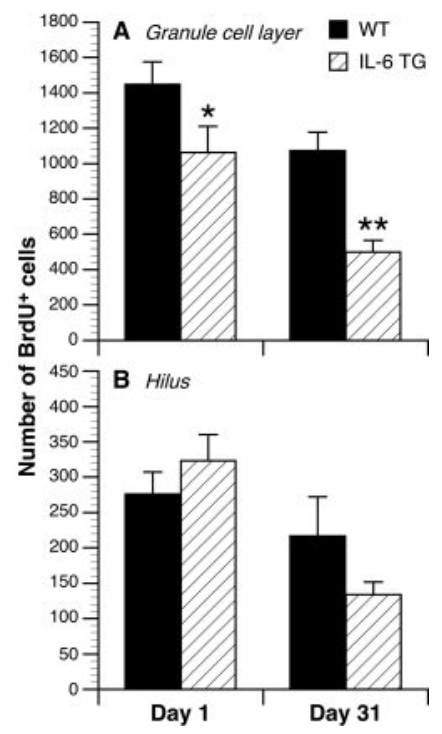

Figure 3. Effect of long-term IL-6 transgene expression on progenitor cell proliferation (day 1) and survival (day 31 ) in the granule cell layer of the dentate gyrus. $A$, Mean \pm SEM of BrdU-labeled cells in the granule cell layer. $B$, Mean \pm SEM of BrdU-labeled cells in the hilar region. $T G$, Transgenic; $W T$, wild-type. ${ }^{*} p=0.05 ; * * p 0.01$.
IL-6, a crucial inflammatory mediator for which expression is induced in the injured brain, might similarly influence the proliferation, survival, and differentiation of hippocampal progenitor cells. The principal finding is that IL-6 instead compromised each of these events when expressed over the long term in the astroglia of young adult transgenic mice. Overall, these animals displayed a $63 \%$ decrease in the production rate of new neurons, whereas progenitor cell distribution and gliogenesis appeared normal. These effects were not the result of any marked toxicity of the IL-6 transgene, because neuronal death was not observed and glial reactivity was mild relative to that seen in response to a short-term insult (seizures). Neural progenitors may have been affected either directly or indirectly by the presence of IL-6 within the hippocampal formation, which was the principal site of IL-6 transgene expression in the forebrain.

The present study attempted to take advantage of the preferential localization of transgene expression to the hippocampal formation to assess the role of IL-6 in postnatal neurogenesis. This focal expression was expected to permit a more specific assessment than what could be achieved, for example, by inf using the cytokine into a brain ventricle. More importantly, the transgenic model permitted analysis of animals in their naive state, unaffected by surgical interventions such as intracerebral cannulation, which inevitably produces brain damage and induces multiple inflammatory mediators that might confound the evaluation of the effects of IL-6. Our model also had the advantage of mimicking long-term IL-6 expression as it is seen in neurological disorders such as Alzheimer's disease (Martinez et al., 2000), multiple sclerosis (Baranzini et al., 2000), and acquired immunodeficiency syndrome dementia (Laurenzi et al., 1990). However, a potential limitation of our approach is that expression of the IL-6 transgene throughout early development could result in congen- 

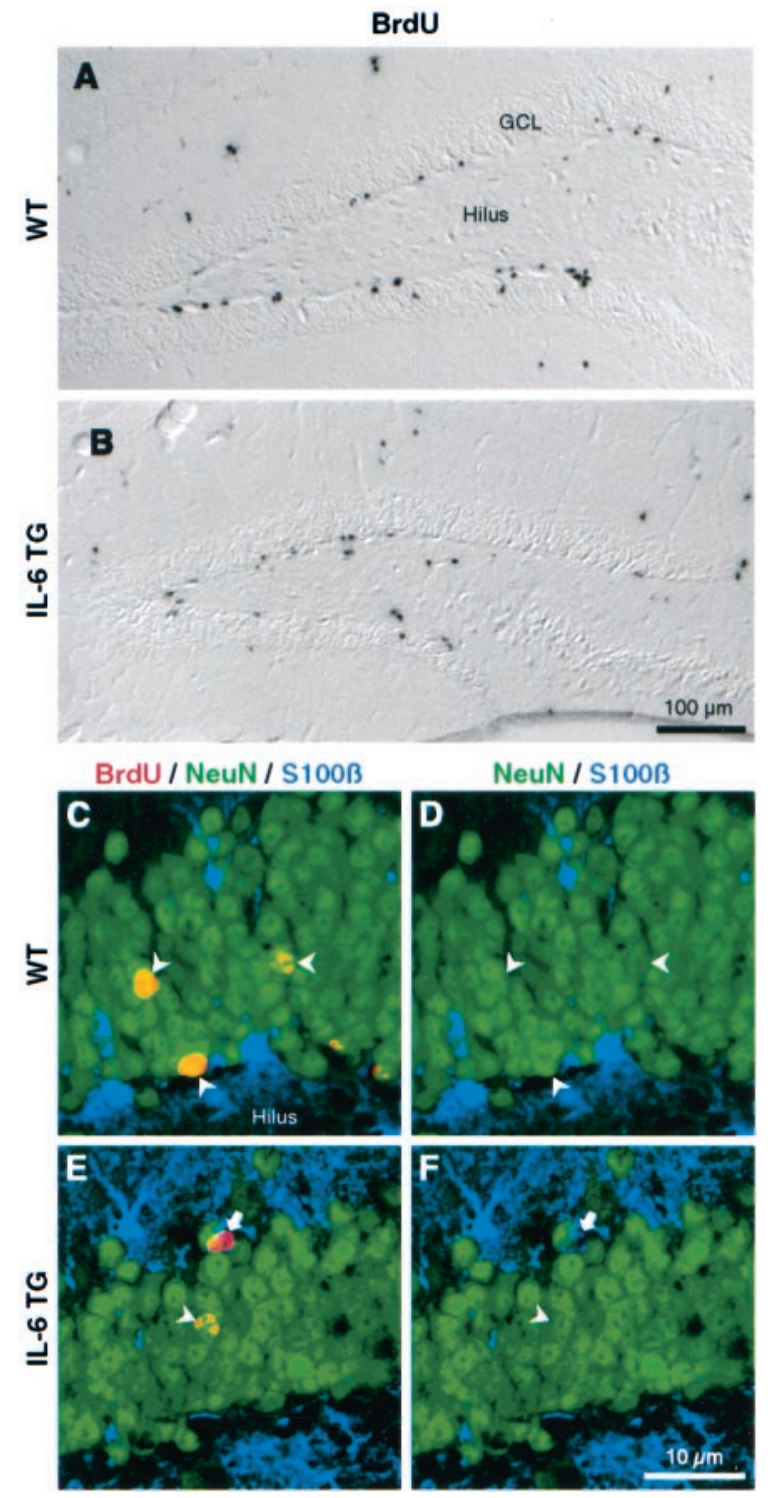

Figure 4. Progenitor cell distribution and phenotype in the dentate gyrus of wild-type and IL-6 transgenic mice. Differential interference contrast images show BrdU-positive cells in the dentate gyrus of wild-type (WT) mice $(A)$ and IL-6 transgenic $(T G)$ mice $(B)$, both killed $1 \mathrm{~d}$ after the final BrdU injection. Merged confocal images show triple immunolabeling for BrdU (red), NeuN (green), and $\mathrm{S} 100 \beta$ (blue) in the granule cell layer of WT $(C)$ and TG $(E)$ mice killed $31 \mathrm{~d}$ after final BrdU injections. $D, F$, The same images as seen in $C$ and $E$, respectively, but without BrdU labeling. GCL, Granule cell layer. Arrowheads indicate BrdU-positive cells double-labeled with NeuN. Arrows indicate BrdU-positive cells not labeled with NeuN.

ital abnormalities that might influence postnatal neurogenesis in any number of direct or indirect ways. Although this possibility cannot be ruled out, we think it is unlikely to have had a major impact, because no between-group difference in the volume of the granule cell layer was noted, and neither major histological abnormalities of the hippocampal formation nor behavioral deficits have been reported in hemizygous IL- 6 transgenic mice at the age examined in this study (Campbell et al., 1993; Heyser et al., 1997).

It has been shown recently that proliferating cells in the subgranular zone of the dentate gyrus constitute a mixed population of endothelial cells and neural precursors (Palmer et al., 2000).

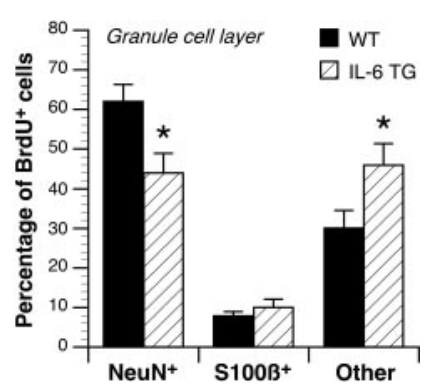

Figure 5. Effect of long-term IL-6 transgene expression on progenitor differentiation in the granule cell layer $31 \mathrm{~d}$ after BrdU injection. Data are expressed as mean \pm SEM of BrdU-labeled cells. $T G$, Transgenic; $W T$, wild-type. ${ }^{*} p<0.01$.

This raises a question as to whether IL-6 influences are exerted similarly on these two cell types. Brain endothelia express the IL-6 receptor (Vallières and Rivest, 1997), which can be upregulated by IL-6 itself (Vallières and Rivest, 1999). This cytokine has been reported to induce cerebral endothelial cells to proliferate and form vessel-like structures in vitro (Fee et al., 2000). In line with these observations, a moderate increase in cerebral vascularity has been observed in hemizygous IL-6 transgenic mice (Campbell et al., 1993). If dividing endothelial cells in the dentate gyrus are in fact more numerous in such mice, the magnitude of the reduction in neural progenitor proliferation reported here would represent an underestimate.

At first glance, it is difficult to reconcile the observations that postnatal neurogenesis is reduced by IL-6 but increased in response to seizure or cerebral ischemia (Bengzon et al., 1997; Parent et al., 1997; Gray and Sundstrom, 1998; Scott et al., 1998; Nakagawa et al., 2000), circumstances that typically induce IL-6 expression. This discrepancy may be attributed to the fact that granule neurons are destroyed in animals subjected to excitotoxic insults, but not in hemizygous IL-6 transgenic mice. Neuronal death may trigger the release of growth factors that promote neurogenesis, thereby counteracting any deleterious effects of IL-6. Moreover, hippocampal progenitors are likely to be exposed to IL-6 for only a relatively short period after acute brain injury, because IL- 6 has been seen to be transiently produced for 3-5 d after excitotoxic lesions (Rosell and McEwen, 2000; L. Vallières and P. Sawchenko, unpublished observations). Such considerations may help explain why the dramatic increase in progenitor cell proliferation observed in the dentate gyrus after seizures or ischemia occurs only after a delay of a few days (Parent et al., 1997; Liu et al., 1998).

IL-6 may affect neurogenesis through a number of distinct mechanisms, whose involvement would be expected to vary as a function of physiological state. IL-6 can act centrally to stimulate the hypothalamo-pituitary-adrenal axis, giving rise to increased circulating glucocorticoids (Turnbull and Rivier, 1999). These steroids have been shown to inhibit cell proliferation and neurogenesis in the dentate gyrus (Gould et al., 1992; Cameron and Gould, 1994). Such a mechanism would likely be invoked in response to infection or traumatic injury, when peripheral or central IL-6 production is massive. In contrast, glucocorticoid involvement may be negligible under conditions in which IL-6 production in the CNS is discrete, or if the hypophysiotropic axis becomes desensitized under conditions of long-term exposure to IL-6. The IL-6 transgenic line used in the present study exhibits normal basal corticosterone levels but exaggerated hormonal responses to stress (Raber et al., 1997), leaving the extent of 
glucocorticoid involvement in the reduced neurogenesis seen in our model open to question.

Alternatively, IL-6 may act directly on progenitors to influence their development, or on neighboring cells to promote the release of paracrine factors involved in regulating neurogenesis. On the one hand, we report that many astrocytes in the dentate gyrus expressed the IL- 6 transgene, providing a potential basis for progenitors to be exposed directly to the cytokine. Recently, neural stem cells have been proposed to be an astrocytic subtype, or at least to express the cytoskeleton filament protein GFAP (Doetsch et al., 1999; Seri et al., 2000), suggesting that neural stem cells themselves may express the IL-6 transgene at certain stages in their development. On the other hand, dentate granule cells express mRNAs encoding both the IL-6-specific receptor subunit (IL-6R) and the signal-transducing subunit (gp130) used by multiple members of this cytokine family (Vallières and Rivest, 1997). The fact that ciliary neurotrophic factor and leukemia inhibitory factor can modulate neural progenitor differentiation raises the possibility that these cells at least produce gp130 (Koblar et al., 1998; Galli et al., 2000; Shimazaki et al., 2001). However, the lack of specific and sensitive antisera has thus far precluded rigorous determination of whether neural progenitors express either of these molecules. Alternatively, after binding its soluble receptor, IL-6 could act on progenitor cells that are devoid of IL-6R but that do express the signal transducer gp130. The available evidence supports the possibility that IL-6 can modulate neurogenesis by acting directly on hippocampal cells, including progenitors, through autocrine and/or paracrine mechanisms.

Embryonic cerebral progenitor cells have been shown to differentiate into astroglia when cultured in the presence of IL-6 or other members of its family, a phenomenon mediated through the Janus kinase/signal transducer and activator of transcription signaling pathway (Bonni et al., 1997). In contrast, we observed no frank alteration in gliogenesis in the granule cell layer of IL-6 transgenic mice, as revealed by $\mathrm{S} 100 \beta$ immunolabeling. It is nevertheless possible that long-term expression of IL- 6 in the hippocampus of these animals may instruct progenitors to adopt a glial fate, thereby reducing neurogenesis, with glial cells dying off at an immature stage of differentiation. Such considerations underscore the fact that molecules identified as regulating neural progenitors in vitro may manifest distinct effects in a more complex in vivo system.

Postnatal neurogenesis generally declines in response to noninjurious stressful conditions (Gould et al., 1997; Eisch et al., 2000; Lemaire et al., 2000), but the functional consequences of this decrement remain largely unknown. Assuming that neurogenesis does play a salutary role in learning and memory (Kempermann et al., 1997, 1998; Gould et al., 1999; Nilsson et al., 1999), the present findings would suggest that long-term expression of IL-6 in CNS disorders and infection can interfere with neurogenesis and contribute to impaired cognitive function. Although this is in line with the observation that age-related cognitive impairment is more pronounced in IL-6 transgenic mice than in wild-type mice (Heyser et al., 1997), the extent to which this can be attributed to cytokine influences on neurogenesis specifically remains to be determined.

Our findings have implications for CNS stem-cell transplantation, because the integration of grafted cells could be compromised in regions displaying pronounced inflammatory reactions. Indeed, a common problem encountered in such transplantation studies is that progenitor cells either die or differentiate into glia.
For example, it has been reported that neural progenitor cells transplanted into the dentate gyrus tend to assume a glial phenotype specifically in areas damaged by the injection procedure (Gage et al., 1995). Thus, we propose that the period of acute inflammation and IL- 6 production that immediately follows brain injury is not optimal for the survival or differentiation of transplanted cells. Thereafter, once IL-6 expression is downregulated and growth factors are released to promote tissue remodeling, conditions may be more favorable for successful stem-cell grafting, although the act of introducing the graft would militate against this to some degree.

In summary, this study provides the first demonstration that a proinflammatory cytokine can repress neurogenesis in the mature brain. Whether other immune system mediators exhibit similar properties, the mechanisms underlying such effects, and their functional consequences remain to be addressed.

\section{REFERENCES}

Abercrombie M (1946) Estimation of nuclear population from microtome sections. Anat Rec 94:239-247.

Baranzini SE, Elfstrom C, Chang SY, Butunoi C, Murray R, Higuchi R, Oksenberg JR (2000) Transcriptional analysis of multiple sclerosis brain lesions reveals a complex pattern of cytokine expression. J Immunol 165:6576-6582.

Bengzon J, Kokaia Z, Elmer E, Nanobashvili A, Kokaia M, Lindvall O (1997) Apoptosis and proliferation of dentate gyrus neurons after single and intermittent limbic seizures. Proc Natl Acad Sci USA 94:10432-10437.

Bonni A, Sun Y, Nadal-Vicens M, Bhatt A, Frank DA, Rozovsky I, Stahl N, Yancopoulos GD, Greenberg ME (1997) Regulation of gliogenesis in the central nervous system by the JAK-STAT signaling pathway. Science 278:477-483.

Brochu S, Olivier M, Rivest S (1999) Neuronal activity and transcription of proinflammatory cytokines, IkappaBalpha, and iNOS in the mouse brain during acute endotoxemia and chronic infection with Trypanosoma brucei brucei. J Neurosci Res 57:801-816.

Cameron HA, Gould E (1994) Adult neurogenesis is regulated by adrenal steroids in the dentate gyrus. Neuroscience 61:203-209.

Cameron HA, Woolley CS, McEwen BS, Gould E (1993) Differentiation of newly born neurons and glia in the dentate gyrus of the adult rat. Neuroscience 56:337-344.

Campbell IL, Abraham CR, Masliah E, Kemper P, Inglis JD, Oldstone MB, Mucke L (1993) Neurologic disease induced in transgenic mice by cerebral overexpression of interleukin 6. Proc Natl Acad Sci USA 90:10061-10065.

Chiang CS, Stalder A, Samimi A, Campbell IL (1994) Reactive gliosis as a consequence of interleukin-6 expression in the brain: studies in transgenic mice. Dev Neurosci 16:212-221.

Doetsch F, Caille I, Lim DA, Garcia-Verdugo JM, Alvarez-Buylla A (1999) Subventricular zone astrocytes are neural stem cells in the adult mammalian brain. Cell 97:703-716.

Eglitis MA, Mezey E (1997) Hematopoietic cells differentiate into both microglia and macroglia in the brains of adult mice. Proc Natl Acad Sci USA 94:4080-4085.

Eisch AJ, Barrot M, Schad CA, Self DW, Nestler EJ (2000) Opiates inhibit neurogenesis in the adult rat hippocampus. Proc Natl Acad Sci USA 97:7579-7584.

Fee D, Grzybicki D, Dobbs M, Ihyer S, Clotfelter J, Macvilay S, Hart MN, Sandor M, Fabry Z (2000) Interleukin 6 promotes vasculogenesis of murine brain microvessel endothelial cells Cytokine 12:655-665.

Gage FH, Coates PW, Palmer TD, Kuhn HG, Fisher LJ, Suhonen JO, Peterson DA, Suhr ST, Ray J (1995) Survival and differentiation of adult neuronal progenitor cells transplanted to the adult brain. Proc Natl Acad Sci USA 92:11879-11883.

Galli R, Pagano SF, Gritti A, Vescovi AL (2000) Regulation of neuronal differentiation in human CNS stem cell progeny by leukemia inhibitory factor. Dev Neurosci 22:86-95.

Gould E, Tanapat P (1997) Lesion-induced proliferation of neuronal progenitors in the dentate gyrus of the adult rat. Neuroscience 80:427-436.

Gould E, Cameron HA, Daniels DC, Woolley CS, McEwen BS (1992) Adrenal hormones suppress cell division in the adult rat dentate gyrus. J Neurosci 12:3642-3650.

Gould E, McEwen BS, Tanapat P, Galea LA, Fuchs E (1997) Neurogenesis in the dentate gyrus of the adult tree shrew is regulated by psychosocial stress and NMDA receptor activation. J Neurosci 17:2492-2498.

Gould E, Beylin A, Tanapat P, Reeves A, Shors TJ (1999) Learning 
enhances adult neurogenesis in the hippocampal formation. Nat Neurosci 2:260-265.

Gray WP, Sundstrom LE (1998) Kainic acid increases the proliferation of granule cell progenitors in the dentate gyrus of the adult rat. Brain Res 790:52-59.

Gross CG (2000) Neurogenesis in the adult brain: death of a dogma. Nat Rev Neurosci 1:67-73.

Heyser CJ, Masliah E, Samimi A, Campbell IL, Gold LH (1997) Progressive decline in avoidance learning paralleled by inflammatory neurodegeneration in transgenic mice expressing interleukin 6 in the brain. Proc Natl Acad Sci USA 94:1500-1505.

Ito D, Imai Y, Ohsawa K, Nakajima K, Fukuuchi Y, Kohsaka S (1998) Microglia-specific localisation of a novel calcium binding protein, Iba1. Brain Res 57:1-9.

Kalman M, Hajos F (1989) Distribution of glial fibrillary acidic protein (GFAP)-immunoreactive astrocytes in the rat brain. I. Forebrain. Exp Brain Res 78:147-163.

Kaplan MS, Bell DH (1984) Mitotic neuroblasts in the 9-day-old and 11-month-old rodent hippocampus. J Neurosci 4:1429-1441.

Kaplan MS, Hinds JW (1977) Neurogenesis in the adult rat: electron microscopic analysis of light radioautographs. Science 197:1092-1094.

Kempermann G, Kuhn HG, Gage FH (1997) More hippocampal neurons in adult mice living in an enriched environment. Nature 386:493-495.

Kempermann G, Kuhn HG, Gage FH (1998) Experience-induced neurogenesis in the senescent dentate gyrus. J Neurosci 18:3206-3212.

Koblar SA, Turnley AM, Classon BJ, Reid KL, Ware CB, Cheema SS, Murphy M, Bartlett PF (1998) Neural precursor differentiation into astrocytes requires signaling through the leukemia inhibitory factor receptor. Proc Natl Acad Sci USA 95:3178-3181.

Kuhn HG, Dickinson-Anson H, Gage FH (1996) Neurogenesis in the dentate gyrus of the adult rat: age-related decrease of neuronal progenitor proliferation. J Neurosci 16:2027-2033.

Laurenzi MA, Siden A, Persson MA, Norkrans G, Hagberg L, Chiodi F (1990) Cerebrospinal fluid interleukin-6 activity in HIV infection and inflammatory and noninflammatory diseases of the nervous system. Clin Immunol Immunopathol 57:233-241.

Lemaire V, Koehl M, Le Moal M, Abrous DN (2000) Prenatal stress produces learning deficits associated with an inhibition of neurogenesis in the hippocampus. Proc Natl Acad Sci USA 97:11032-11037.

Liu J, Solway K, Messing RO, Sharp FR (1998) Increased neurogenesis in the dentate gyrus after transient global ischemia in gerbils. J Neurosci 18:7768-7778.

Markakis EA, Gage FH (1999) Adult-generated neurons in the dentate gyrus send axonal projections to field CA3 and are surrounded by synaptic vesicles. J Comp Neurol 406:449-460.

Martinez M, Fernandez-Vivancos E, Frank A, De la Fuente M, Hernanz A (2000) Increased cerebrospinal fluid fas (Apo-1) levels in Alzheimer's disease: relationship with IL-6 concentrations. Brain Res 869:216-219.

Munoz-Fernandez MA, Fresno M (1998) The role of tumour necrosis factor, interleukin 6, interferon-gamma and inducible nitric oxide synthase in the development and pathology of the nervous system. Prog Neurobiol 56:307-340.

Nakagawa E, Aimi Y, Yasuhara O, Tooyama I, Shimada M, McGeer PL, Kimura H (2000) Enhancement of progenitor cell division in the dentate gyrus triggered by initial limbic seizures in rat models of epilepsy. Epilepsia 41:10-18.

Nilsson M, Perfilieva E, Johansson U, Orwar O, Eriksson PS (1999)
Enriched environment increases neurogenesis in the adult rat dentate gyrus and improves spatial memory. J Neurobiol 39:569-578.

Okano HJ, Pfaff DW, Gibbs RB (1993) RB and Cdc2 expression in brain: correlations with ${ }^{3} \mathrm{H}$-thymidine incorporation and neurogenesis. J Neurosci 13:2930-2938.

Palmer TD, Willhoite AR, Gage FH (2000) Vascular niche for adult hippocampal neurogenesis. J Comp Neurol 425:479-494.

Parent JM, Yu TW, Leibowitz RT, Geschwind DH, Sloviter RS, Lowenstein DH (1997) Dentate granule cell neurogenesis is increased by seizures and contributes to aberrant network reorganization in the adult rat hippocampus. J Neurosci 17:3727-3738

Peters M, Muller AM, Rose-John S (1998) Interleukin-6 and soluble interleukin-6 receptor: direct stimulation of gp130 and hematopoiesis. Blood 92:3495-3504.

Raber J, O'Shea RD, Bloom FE, Campbell IL (1997) Modulation of hypothalamic-pituitary-adrenal function by transgenic expression of interleukin-6 in the CNS of mice. J Neurosci 17:9473-9480.

Rosell DR, McEwen BS (2000) Interleukin-6 (I1-6), Il-6 receptor expression in the rat hippocampus in response to status epilepticus: time-course, distribution, correlation with neuronal degeneration. Soc Neurosci Abstr 26:1617.

Scheffler B, Horn M, Blumcke I, Laywell ED, Coomes D, Kukekov VG, Steindler DA (1999) Marrow-mindedness: a perspective on neuropoiesis. Trends Neurosci 22:348-357.

Schmued LC, Albertson C, Slikker Jr W (1997) Fluoro-Jade: a novel fluorochrome for the sensitive and reliable histochemical localization of neuronal degeneration. Brain Res 751:37-46.

Scott BW, Wang S, Burnham WM, De Boni U, Wojtowicz JM (1998) Kindling-induced neurogenesis in the dentate gyrus of the rat. Neurosci Lett 248:73-76.

Seri B, Garcia-Verdugo JM, Alvarez-Buylla A (2000) Identification of the neural stem cells in the adult hippocampus. Soc Neurosci Abstr 26:825.

Shimazaki T, Shingo T, Weiss S (2001) The ciliary neurotrophic factor/ leukemia inhibitory factor/gp130 receptor complex operates in the maintenance of mammalian forebrain neural stem cells. J Neurosci 21:7642-7653

Shors TJ, Miesegaes G, Beylin A, Zhao M, Rydel T, Gould E (2001) Neurogenesis in the adult is involved in the formation of trace memories. Nature 410:372-376.

Stanfield BB, Trice JE (1988) Evidence that granule cells generated in the dentate gyrus of adult rats extend axonal projections. Exp Brain Res 72:399-406.

Turnbull AV, Rivier CL (1999) Regulation of the hypothalamicpituitary-adrenal axis by cytokines: actions and mechanisms of action. Physiol Rev 79:1-71.

Turski WA, Cavalheiro EA, Bortolotto ZA, Mello LM, Schwarz M, Turski L (1984) Seizures produced by pilocarpine in mice: a behavioral, electroencephalographic and morphological analysis. Brain Res 321:237-253.

Vallières L, Rivest S (1997) Regulation of the genes encoding interleukin-6, its receptor, and gp130 in the rat brain in response to the immune activator lipopolysaccharide and the proinflammatory cytokine interleukin-1beta. J Neurochem 69:1668-1683.

Vallières L, Rivest S (1999) Interleukin-6 is a needed proinflammatory cytokine in the prolonged neural activity and transcriptional activation of corticotropin-releasing factor during endotoxemia. Endocrinology 140:3890-3903 